\title{
Skeletal morphology and maturation of male Gambusia holbrooki exposed to sewage treatment plant effluent
}

\author{
Christopher A. Rawson ${ }^{\mathrm{a}}{ }^{\star}$, Richard P. Lim ${ }^{\mathrm{a}}$, Michael St.J. Warne ${ }^{\mathrm{b}}$ \\ ${ }^{a}$ Institute for Water and Environmental Resource Management (IWERM) and Department of Environmental Sciences, University of Technology, \\ Sydney (UTS), Broadway, NSW 2007, Australia \\ ${ }^{\mathrm{b}}$ CSIRO, Centre for Environmental Contaminants, PMB 2, Glen Osmond SA 5064, Australia
}

\begin{abstract}
Sewage effluent has been identified as a major source of endocrine disrupting chemicals (EDCs) in the aquatic environment. The modified hemal spines (modified skeletal structures important in reproduction) of mosquitofish, Gambusia spp. have been shown to be under androgenic control and to be affected by exposure to estrogen. The current study aimed to investigate the effects of two sewage treatment plants (STPs) in Sydney, Australia on the morphology of hemal spines in populations of Gambusia holbrooki and on the ability of the fish to reach sexual maturity. The effluent from the two STPs had different effects on the hemal spines of males. At St. Marys differences in hemal spine morphology between fish upstream and downstream of the STP were not attributable to effluent from the STP. At Quakers Hill, results suggest that the effluent is generally estrogenic to G. holbrooki. There was a decrease in the proportion of males that were morphologically mature downstream of both STPs indicating potential population level effects that were associated with the presence of the STPs.
\end{abstract}

Keywords: Endocrine disruption; Gambusia holbrooki; Sewage treatment plant; Hemal spines; Estrogenic; Australia

\section{Introduction}

Endocrine disrupting chemicals (EDCs) are a major contaminant of sewage treatment plant (STP) effluent (Ternes et al., 1999a, b; Baronti et al., 2000; Pawlowski et al., 2004). They are derived from industrial, agricultural and domestic sources and include pesticides, herbicides, detergents, industrial by-products and their breakdown products, and synthetic and natural hormones (RodgersGray et al., 2000). Numerous studies have identified endocrine disruption downstream of STPs. The induction of vitellogenin, a female-specific protein, in males has been used to demonstrate estrogenic effects of STP effluent on a number of species (e.g. longear sunfish (Porter and Janz, 2003), rainbow trout (Purdom et al., 1994), roach (Lye et al., 1997)). The abnormal development of gonads (e.g. Lye et al., 1997; Jobling et al., 2002), and secondary sexual

\footnotetext{
*Corresponding author. Fax: +61295144201.

E-mail address: Christopher.A.Rawson@uts.edu.au (C.A. Rawson).
}

characteristics (e.g. Batty and Lim, 1999; Doyle et al., 2003) have also been observed in fish populations downstream of STPs.

Poeciliids are sexually dimorphic, fresh to brackish water fish that are considered ideal bioindicators for the presence of EDCs (Batty and Lim, 1999; Angus et al., 2002; Doyle et al., 2003). Males are physically smaller than females and possess an elongated anal fin (gonopodium), which is used in copulation (Collier, 1936). The delayed development and failure to reach morphological maturity of the gonopodium have been used previously to assess the anti-androgenic effects of exposure to estrogenic compounds. Doyle and Lim (2002) showed that exposure to 17b-estradiol resulted in a dose-dependant reduction in gonopodial characteristics. Brennan et al. (2003) used reduced gonopodial characteristics and lowered sexual behaviour in Gambusia holbrooki in a field study to show the presence of endocrine disruption in a remediated site, while Batty and Lim (1999) found reduced development of the gonopodium in the same species downstream of an STP. 
The development of the gonopodium is preceded and accompanied by modifications to skeletal structures and accessory ligaments of male poeciliids (Kuntz, 1914). The anterior-most hemal spines are strongly dimorphic with those of males being elongated, thickened, bent anteriorly, and often form uncinatoid processes while those of females remain similar in size and shape relative to body size (Fig. 1a-c) (Rosen and Gordon, 1953). This anterior bending pushes the gonopodium forward and into line with the centre of gravity of the fish allowing efficient swinging of the gonopodium during copulation (Rosen and Gordon, 1953; Bond, 1979). The elongation and anterior bending of the hemal spines on the 14th, 15th, and 16th vertebrae are under androgenic control (Turner, 1942) and the process requires increasing concentrations of androgen to proceed to completion (St. Amant, 1941, cited in Turner, 1942).

Male Gambusia spp. possess modified hemal spines on the 14th, 15th, and 16th vertebrae (Rosa-Molinar et al., 1994) (Fig. 1a). The modifications to these hemal spines begin prior to the development of the gonopodium. It has been
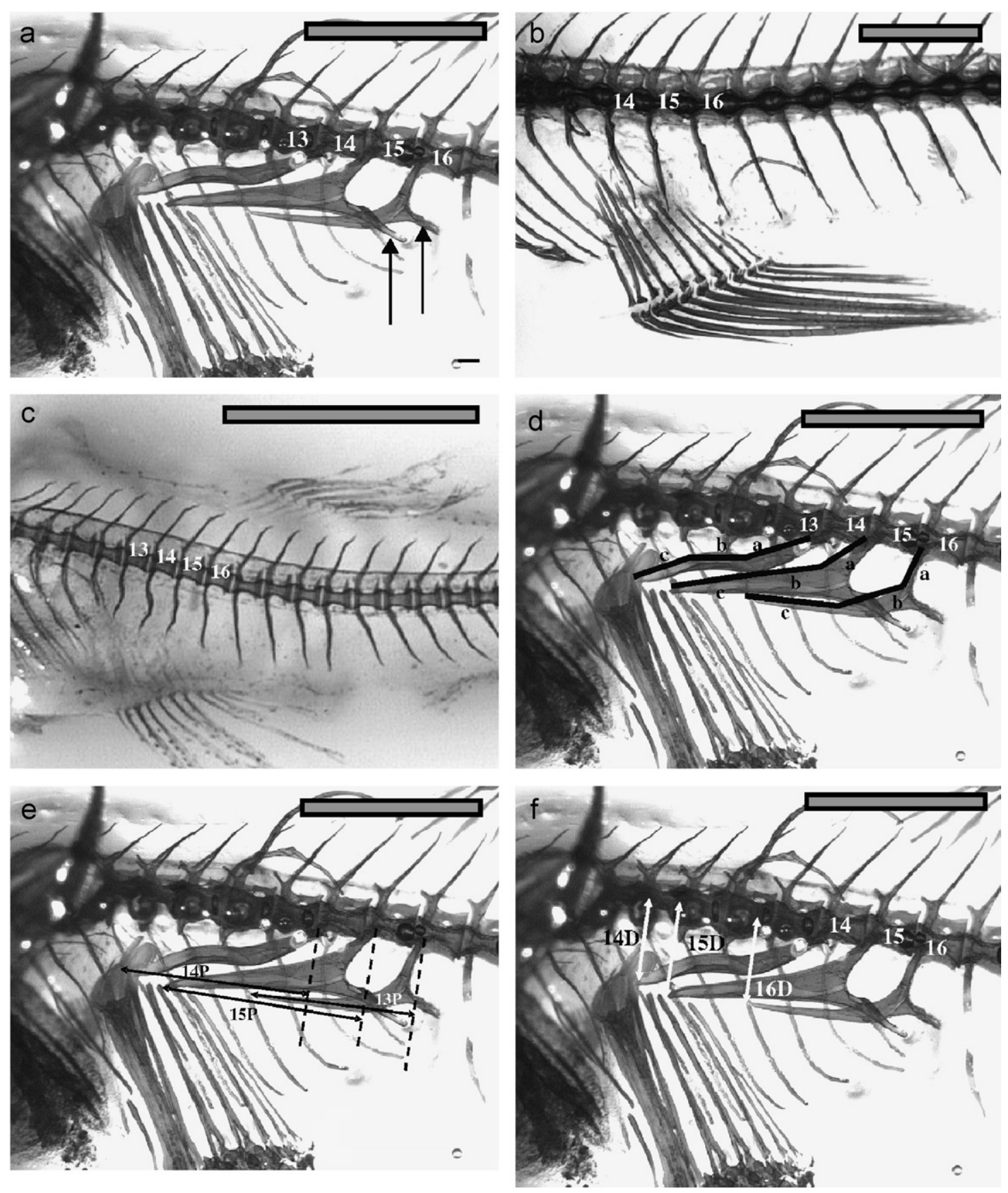

Fig. 1. Skeletal morphology of (a) male (large arrow indicates uncinatoid process), (b) female, and (c) juvenile male G. holbrooki, and measurements made on the 14th, 15th, and 16th hemal spines; (d) total length (L) of the hemal spine was calculated as the sum of a, b and c for each spine, (e) perpendicular distance (P) from the point of attachment to the tip of each spine, (f) "depth" (D) measured from the distal tip of the spine to the vertebral column. Modified from Rawson et al. (2006). 
shown that exposure to a model EDC delays the development of hemal spines in early life-stage male G. holbrooki (Rawson et al., 2006). Rawson et al. (2006) showed that at 8 weeks of age there was a reduction in the lengthening and anterior bending processes in fish exposed to high $(500 \mathrm{ng} / \mathrm{L})$ concentrations of $17 \mathrm{~b}$-estradiol. Both processes, along with the bending of the spine toward the vertebral column of the fish are likely to be important in correct hemal spine development. The modified hemal spine must be longer than its unmodified counterparts in order to push the gonopodium into the optimum position for copulation. For a similar reason, the distance that the spine is bent forward is important. Further, the amount that the spine is bent up towards the vertebral column is likely to be important in providing a solid anchor for the accessory ligaments used in the forward swinging of the gonopodium. The early lifestages are particularly sensitive to exposure to EDCs. It is, therefore, important to investigate effects that occur early in life and may persist to maturity.

In Australia, there is limited literature addressing the effects of EDCs on fish. Further, there are few studies showing endocrine disrupting effects at a population level or on endpoints that can be generalised to population level effects. The differences in climatic factors, treatment methods, and biota in Australia necessitate further examination of this important type of anthropogenic pollution. In addition, there is currently significant political and social debate, fuelled by a widely recognised shortage of water, on the reuse of treated wastewater as domestic potable supply. It is, therefore, important to provide information to managers regarding the possibility of pollutants contained in STP effluent and any possible effects to ecological and human health.

The aim of this study was to examine the effects of exposure to effluent from two STPs near Sydney, NSW, Australia, employing different treatment technologies, on the males of G. holbrooki populations using the morphology of the modified hemal spines (specifically the length and degree of forward movement) as a marker for early life-stage endocrine disruption and the level of sexual maturity (based on gonopodial morphology) present in the male populations inhabiting these sites. It was hypothesised that fish exposed to effluent contaminated waters immediately downstream of the STPs would show reduced development of these markers.

\section{Materials and methods}

The reaches of two waterways each affected by a single STP were examined. St. Marys STP discharges approximately $37 \mathrm{ML}$ per day of tertiary treated sewage effluent into a small tributary of South Creek (Lovell et al., 2000) (Fig. 2). Influent to St. Marys STP is treated by screening and gritting, sedimentation, anaerobic fermentation, anoxic denitrogenation, aerobic fermentation, phosphorus removal by aeration and coagulation/flocculation, dual media filter (sand and anthracite), and disinfection with chlorine (Sydney Water, 2002b).

Quakers Hill STP discharges approximately $32 \mathrm{ML}$ per day of tertiary treated sewage effluent into Breakfast Creek, a small tributary of Eastern Creek (Lovell et al., 2000) (Fig. 2). Influent is treated by screening and gritting, nitrification by aeration, denitrification in a settling process,

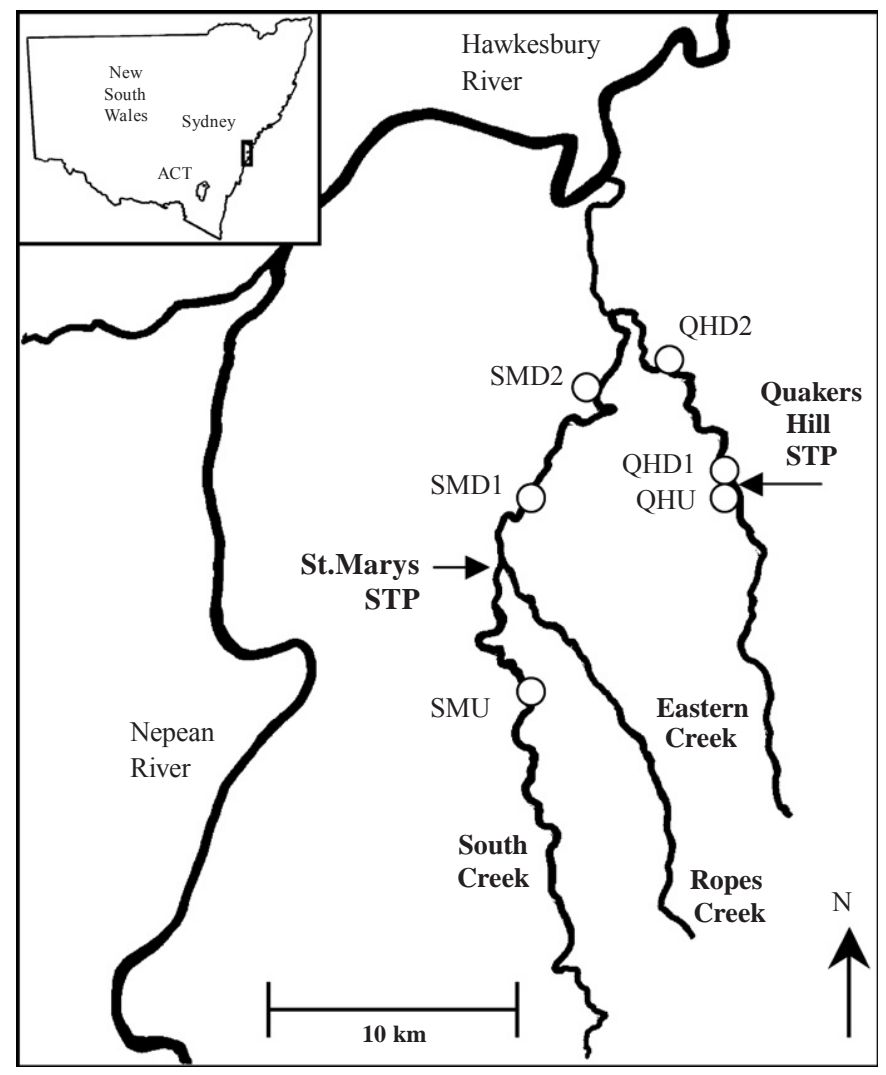

Fig. 2. Locations of sample sites within the Hawkesbury-Nepean River System, NSW.

decanting of the clear effluent, flocculation of remaining solids, clarification, tertiary filters, and chlorination (Sydney Water, 2002a). The two STPs receive influent from similar sources (mainly domestic with small amounts of commercial/industrial) (Sydney Water, 2002a, b).

\subsection{Sites}

For each STP one site upstream and two sites downstream of the outflow were sampled (Fig. 2). Sites were chosen for accessibility, presence of G. holbrooki habitat and ease of sampling. The site upstream of St. Marys STP (SMU) was located generally in urban precinct approximately $5 \mathrm{~km}$ upstream of the STP outflow. The two sites downstream of this STP (SML1 and SML2) were located 4 and $7 \mathrm{~km}$ downstream from the outflow, respectively. Both these downstream sites were located in light agricultural land. The site upstream from the Quakers Hill STP (QHU) was located $400 \mathrm{~m}$ above the outflow. The site immediately downstream of the Quakers Hill STP (QHL1) was located approximately $600 \mathrm{~m}$ from of the outflow from the STP before the confluence with Eastern $\mathrm{Ck}$. These sites were located in a low-density urban area. The site further downstream $(5 \mathrm{~km})$ of the Quakers Hill STP (QHL2) on Eastern Creek is surrounded by agricultural land (Fig. 2).

Both QHU and SMU have been used in previous studies (Batty and Lim, 1999; Doyle et al., 2003) as reference sites and are considered to be outside the limit of tidal influence and therefore not exposed to effluent from the STPs.

\subsection{Sampling and processing of fish}

G. holbrooki were caught using an aquatic dip net and transported to the laboratory and held until processing (max. $48 \mathrm{~h}$ ). They were sorted into sexually mature (adult) males (i.e. those possessing hooks at the distal tip 
of the gonopodium (gonopodial hooks)), females and immature (juvenile-those which are morphologically identifiable as male but which do not possess gonopodial hooks) male fish. Adult and juvenile males were sacrificed (using $400 \mathrm{mg} / \mathrm{L}$ benzocaine) and photographed using a Leica DC 100 digital camera mounted on a stereomicroscope and preserved in $70 \%$ ethanol. The methods for the preparation and staining of skeletons are described in Rawson et al. (2006). Briefly, the tissue was removed by immersion in $1 \%$ potassium hydroxide $(\mathrm{KOH})$ and the skeletons stained with a $1 \%$ Alizarin red $\mathrm{S}$ solution.

\subsection{Endpoints measured}

The stained skeletons were photographed using a Leica DC 100 digital camera mounted on a stereomicroscope. Measurements were made on the resulting images using Leica Qwin Standard (v.2.3) image analysing software (r 1993-1998 Leica Microsystems Imaging Solutions, North Ryde, Sydney).

Measurements were made on all captured adult (as defined above) and juvenile males. Measurements taken followed those developed by Rawson et al. (2006). These were the total hemal spine length (L), the perpendicular distance from the point of attachment of the hemal spine to its distal tip $(\mathrm{P})$, and the perpendicular distance from the distal tip of the hemal spine to the centre of the vertebral column (D) (Fig. 1d-f). Endpoints measured, the abbreviations used to describe them in the text and the direction of normal male development for each are summarised in Table 1. While Rawson et al. (2006) examined fish in very early life-stage (i.e. 8 and 12 weeks post partum) where the perpendicular distance, $\mathrm{P}$, was negative (i.e. PO0) for many individuals, all the fish captured and analysed in the present study were males with $\mathbf{P} 40$.

It has been shown in laboratory studies that the development of the hemal spines of early life-stage G. holbrooki is sensitive to exposure to estrogenic EDCs at 8 weeks post partum but that at 12 weeks there are fewer discernible differences over a population of males and females due to greater sexual differentiation (Rawson et al., 2006). Here, with females removed such differences are not artefacts of the analyses. In this case only male fish older than 12 weeks of age (observed to be the average age at which sex can be morphologically determined) were examined. Any differences observed are, therefore, likely to be caused from exposure to EDCs at an early life-stage.

\subsection{Statistical analyses}

Each measure was analysed using analysis of covariance (ANCOVA) with the standard length (SL) of the fish as a covariate thereby accounting for allometry. The assumption of homogeneous linear regressions was tested and was met for each data set. Post hoc comparisons were made using Tukeys pairwise comparisons. As there were many ANCOVAs performed on the same datasets, a Bonferonni procedure was used to adjust the significance level to maintain the Type I family error rate. Where the assumptions of the analysis were not met the non-parametric Kruskal-Wallis test was used and post hoc comparisons made with the Mann-Whitney U-test. The proportion of adult males at each site was examined using a chi-squared test using the value at the upstream sites as an expected value in the downstream sites.

\section{Results}

\subsection{St. Marys}

In both adult and juvenile males at St. Marys, there were significant (Pp0.05) differences on measured endpoints on the hemal spines on the 16th vertebra between fish inhabiting sites upstream and downstream of the STP (Fig. 3). Both $16 \mathrm{~L}$ and $16 \mathrm{P}$ were greater $(\mathrm{Pp} 0.05)$ in adult males from SML2 (n $1 / 4$ 20) than those from SMU (n $1 / 426)$ (Figs. 3a and b) while adult fish from SML1 (n $1 / 4$ 14) showed no significant (P40.05) difference with males from either of the other two sites with respect to these endpoints. $16 \mathrm{~L}$ and $16 \mathrm{D}$ were longer in juvenile males at SML1 (n $1 / 4$ 53) than that in fish from SMU (n 1/4 36) (Fig. 3c) and were intermediate for fish from SML2 (n $1 / 411$ ), such that there was no significant difference (P40.05) between fish from SML2 and those from the other two sites. There were no o ther statistically significant (P40.05) differences observed in the hemal spines of males from the St. Marys sites.

There was a significant decrease in the proportion of males with gonopodial hooks (adult males) from SMU $(42 \%)$ to SML1 (21\%) (Fig. 4a). Further there was an increase in this proportion further downstream at SML2 (39\%) such that this was not significantly different from that at SMU.

\subsection{Quakers Hill}

The endpoints measured on the hemal spines of adult males at Quakers Hill varied significantly (Pp 0.05)

Table 1

Summary of endpoints measured, the abbreviations used in the text and the direction of normal male development for each

\begin{tabular}{|c|c|c|c|c|}
\hline \multirow[t]{2}{*}{ Hemal spine endpoint } & \multirow[t]{2}{*}{ spine } & \multirow[t]{2}{*}{ Abbreviation } & \multicolumn{2}{|l|}{ Form of male development } \\
\hline & & & Early juvenile (PO0) & Late juvenile (P40) \\
\hline $\begin{array}{l}\text { Perpendicular distance } \\
\text { from tip to attachment } \\
\text { (P) }\end{array}$ & $\begin{array}{l}14 \\
15 \\
16\end{array}$ & $\begin{array}{l}14 \mathrm{P} \\
15 \mathrm{P} \\
16 \mathrm{P}\end{array}$ & From negative towards 0 & Increase \\
\hline $\begin{array}{l}\text { Distance from tip to } \\
\text { vertebrae (D) }\end{array}$ & $\begin{array}{l}14 \\
15 \\
16\end{array}$ & $\begin{array}{l}14 \mathrm{D} \\
15 \mathrm{D} \\
16 \mathrm{D}\end{array}$ & Increase & Decrease \\
\hline
\end{tabular}

In the current study all fish had P40. 
a

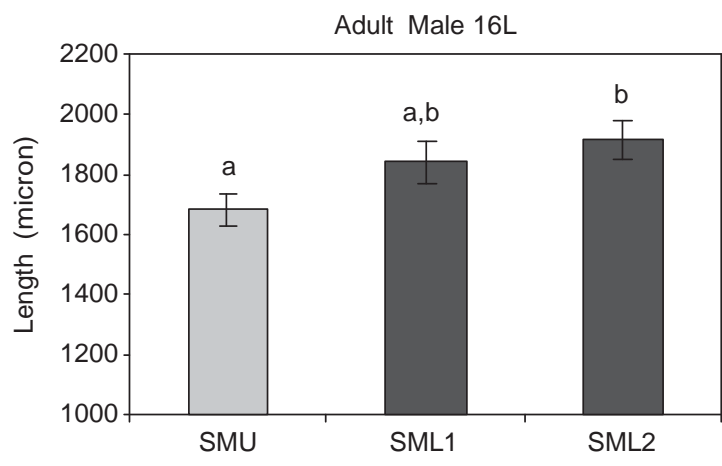

b

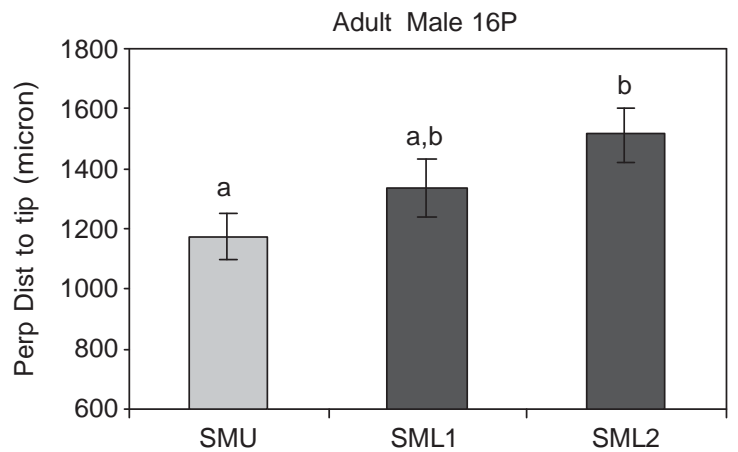

C

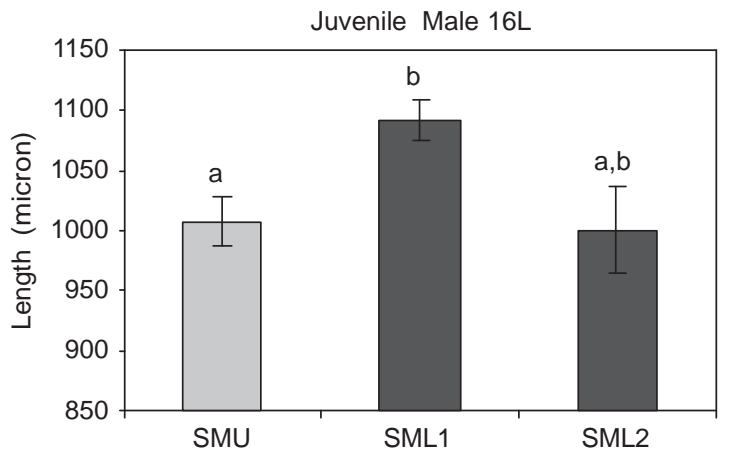

d

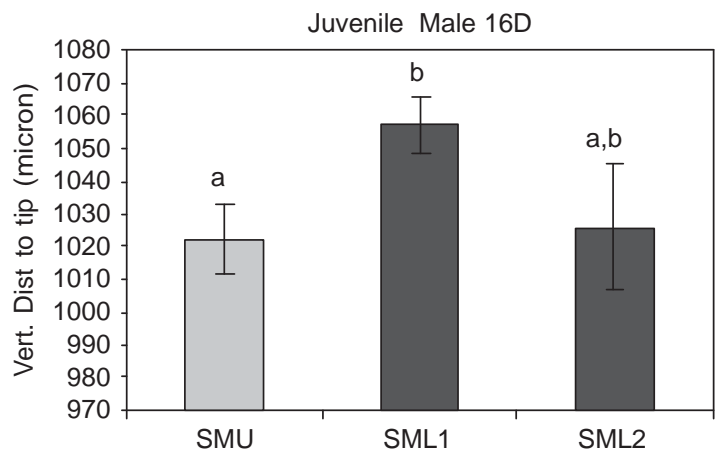

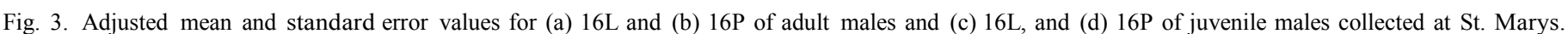

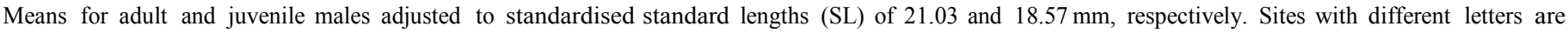
significantly (PO0.05) different.

between sites only in 15D and 14D (Fig. 5a and b). At QHL1 (n $1 / 416)$ the 15D lengths in males were significantly greater (Pp0.05) than that in males from QHU (n 1/4 11) and QHL2 (n 1/4 12), which were not significantly different (P40.05) from each other (Fig. 5a). The 14D of males from QHL1 was significantly greater (Pp 0.05$)$ compared to those of males from either QHU or QHL1 (Fig. 5b), which were not significantly different (P40.05) from each other.

There were more significant (Pp0.05) differences between the hemal spines of juvenile males at Quakers Hill sites than in adult males. The $15 \mathrm{P}$ in juvenile males was significantly shorter (Pp0.05) in individuals from QHL1 (n $1 / 471)$ than those from QHU (n $1 / 426)$ and QHL2 (n $1 / 442)$ while the lengths in males from these two sites were not significantly different (P40.05) to each other (Fig. 5c). The measures of 16D, 15D, and 14D varied significantly (PO0.05) in juvenile males at Quakers Hill (Fig. 5d-f). For each hemal spine D was significantly greater $(\mathrm{Pp} 0.05)$ in fish from QHL1 than in those from QHU. At QHL1 the 16D distances were not significantly (P40.05) different to that of males from QHL2 while for both 15D and 14D there was a significant difference (Pp0.05) between males from these two sites.

There was no significant difference in the proportion of males with gonopodial hooks (adult males) between either of the downstream sites and QHU.

\section{Discussion}

The current study does not attempt to compare the effects of the two STPs and the efficacy of their treatment technologies with respect to the removal of EDCs due to differences in catchment influences, and STP treatment methods. Rather it investigates the two STPs separately and their effects are discussed in this light.

The results of the $\mathrm{L}$ and $\mathrm{P}$ endpoints on the hemal spines of adult fish collected at St. Marys suggest that the fish at the furthest downstream site (SML2) showed more masculine characteristics than those in the upstream site (SMU). In particular, they i ndicate that there were neither feminising nor masculinising effects that can be directly attributed to effluent from the St. Marys STP as there was no difference in the endpoints measured between fish collected from the site upstream of the STP and that directly downstream of it (SML1). The trend (SMU to SML2) is monotonic suggesting that effects are more likely due to multiple or diffuse sources of androgenic EDCs along the stream reach studied. While we believe that this is the most likely explanation given the fact that the land use downstream reaches is mainly agriculture it is also possible that the increase in masculine secondary sexual characteristics is due to an improvement of stream health and fish habitat downstream.

The effects on the juvenile males at St. Marys were consistent with the occurrence of neither feminising nor 


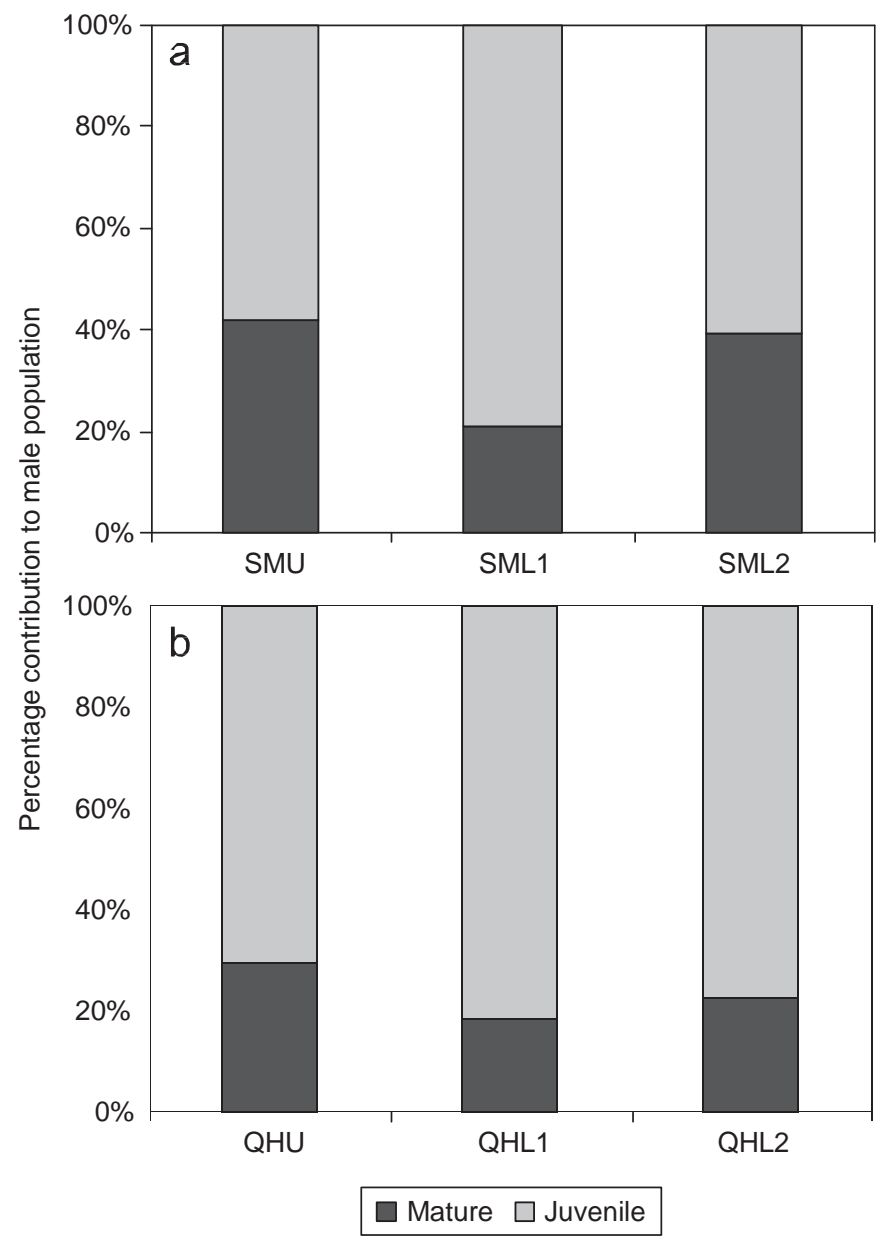

Fig. 4. Percentage contribution to male populations at (a) St. Marys and (b) Quakers Hill by adult (indicated by the presence of a terminal complex of hooks) and juvenile (absence of hooks) males.

masculinising effects. Rawson et al. (2006) suggest that an increase in $16 \mathrm{~L}$ is seen as an increase in masculine characteristics (a masculinising effect), while the increase in $16 \mathrm{D}$ is seen as a decrease in masculine characteristics (a feminising effect) where P40 (as was the case for all males in the current study). The trend observed in juvenile males contrasts with the effect on adult males in that it followed that which would be expected if there were effects associated with the location of the STP. This suggests that while the STP effluent may have an effect on juvenile males, those individuals that reach maturity (i.e. develop gonopodial hooks) are those individuals able to resist its impact and therefore do not show signs of these effects or that the increase in endogenous androgen associated with maturation is sufficient to counteract the observed effect of exogenous estrogenic compounds. It is difficult to resolve these issues based on the present data and a controlled exposure to sewage effluent conducted on juvenile individuals to maturity with time-integrated analyses of the development of reproductive morphology is suggested.

Batty and Lim (1999) found significantly shorter gonopodial lengths in males downstream of St. Marys
STP compared to a site upstream. Their study pooled all data on males (adult and juvenile) into four size classes to account for allometry. Similarly Doyle et al. (2003) showed a decrease in the gonopodium length between the same two sites refining the above analyses by incorporating the standard length of the fish into the analysis. The current study has attempted to further refine this method by separating adult and juvenile fish while incorporating the standard length of the fish into the analysis. The results of the present study provide an interesting contrast to those presented by the two previous studies (i.e. estrogenic effects were attributable to the STPs). The apparent differences in results may point to different mechanistic developmental pathways of the gonopodium and hemal spines and/or that they occur at different critical stages of development.

It has been shown that there is significant inter- and intra-annual variation in the composition of STP effluent (Rodgers-Gray et al., 2000) which could account for the variation observed $h$ ere. These inconsistent responses observed in fish downstream of St. Marys STP indicate the necessity for a further examination of the chemical composition of the water in the stream and a toxicity identification and evaluation (TIE) assessment of EDCs in the water. Further, a detailed study of land use in the area would contribute valuable information on possible sources of EDCs in the catchment.

There were consistent feminising trends at Quakers Hill in both adult and juvenile males, which appear to be closely associated with the presence of the STP (i.e. they are strongest at the first site downstream of the STP decrease with distance from the STP). The proximity of QHU and QHL1 (400 and $600 \mathrm{~m}$, respectively) to the STP outflow suggests that it is likely that any difference between these two sites is caused by the effluent. Doyle et al. (2003) studied the impact of the Quakers Hill STP on the gonopodial characteristics of populations of G. holbrooki and found no significant (P40.05) difference but in our study the hemal spine results clearly suggest a feminising effect.

Interestingly, the differences observed in the fish at Quakers Hill occurred on the hemal spines on the 14th and 15 th vertebrae unlike those observed at St. Marys where all differences were observed on the hemal spine on the 16th vertebra. The differing directions of the responses (generally masculinising at St. Marys and generally feminising at Quakers Hill) could account for this, given that exposure to an androgen is likely to accelerate and exposure to an estrogen will delay development of the hemal spines (Turner, 1942; Rawson et al., 2006). The results suggest that the hemal spine on the 16th vertebra will develop first (hence will have the greatest acceleration in development upon exposure to androgenic substances) followed by those on the 14th and 15th vertebrae, the development of which will be more delayed with exposure to estrogenic substances.

At St. Marys there was a decrease in the proportion of adult individuals in the male populations at sites 
a

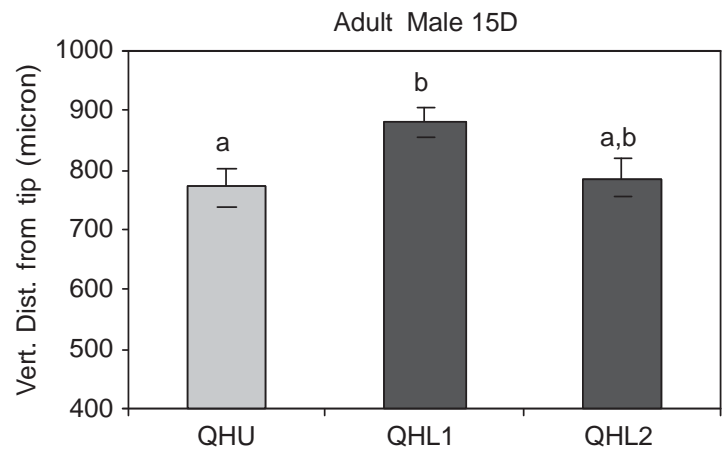

b

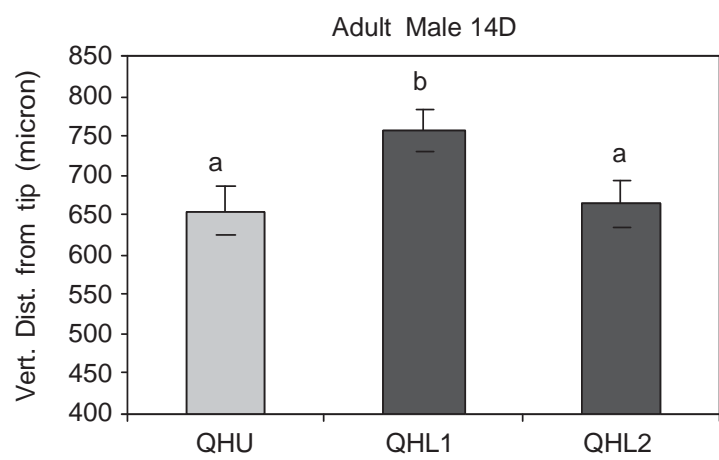

C

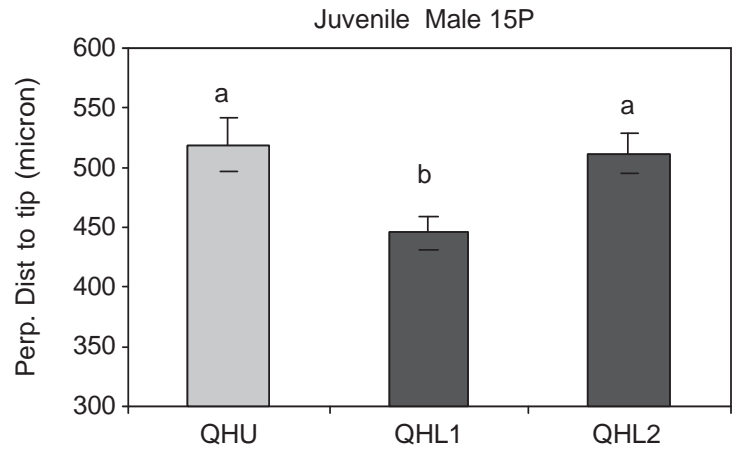

d

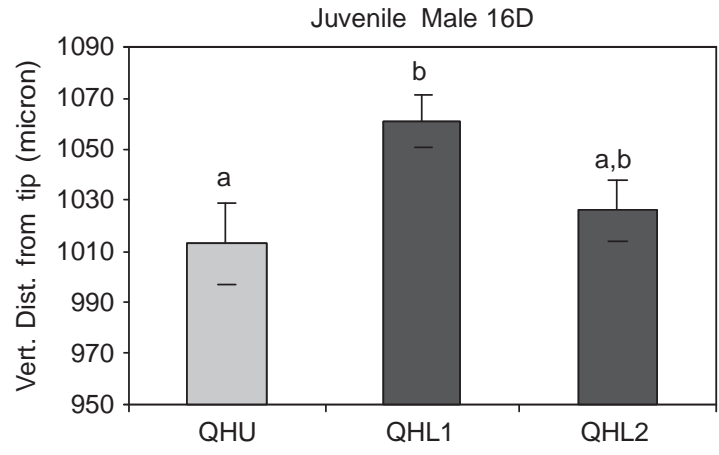

e

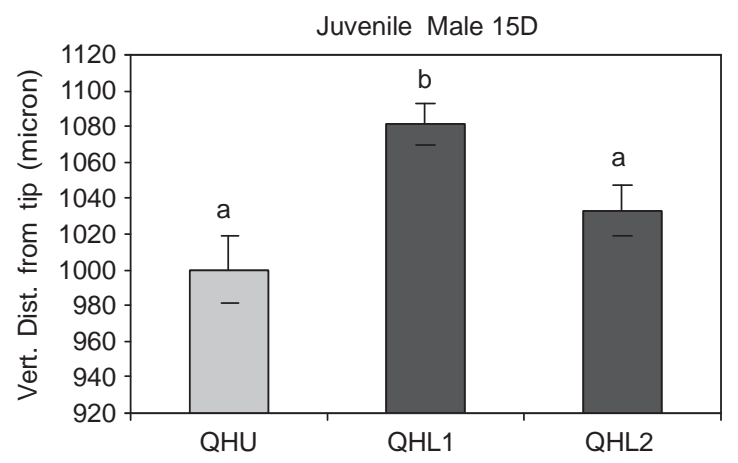

f

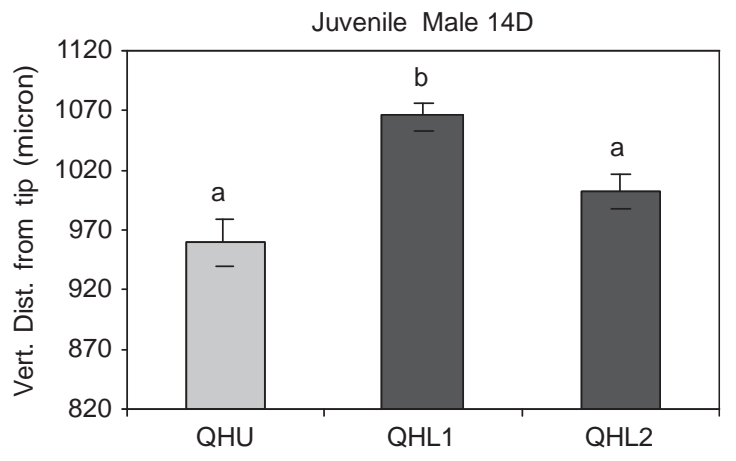

Fig. 5. Adjusted mean and standard error values for (a) 15D and (b) 14D of adult males and (c) 15P, (d) 16D, (e) 15D, and (f) 14D of juvenile males collected at Quakers Hill. Means for adult and juvenile males are adjusted to standardised standard lengths (SL) of 21.46 and $18.74 \mathrm{~mm}$, respectively. Sites with different letters are significantly (PO0.05) different.

downstream of the STP. Further, there was an increase in this proportion at the sites further downstream. Given the relatively high site specificity of the species (Pyke, 2006) and, therefore, a low likelihood of adult migration causing this trend, this suggests that the males at the sites closest to the STP were experiencing either a delay in achieving maturity (the development of hooks) or a blocking of this process in sensitive individuals (both feminising effects). This is an important finding as it indicates a potential population level response to the presence of the STP. Doyle and Lim (2002) found that males exposed to 17b-estradiol can fail to develop gonopodial hooks. The same authors demonstrated that, e ven where males reach maturity (develop gonopodial hooks), exposed to EDSs causes a decrease in sex drive and are therefore likely to experience reduced reproductive fitness (Doyle and Lim, 2005). It follows that populations with a reduction in the development of gonopodial hooks will experience a decrease in reproductive fitness.

While one of the two STPs studied showed no estrogenic effect on the morphology of the fish inhabiting waters downstream of its outfall, a similar STP nearby did. This highlights the difficulty in generalising trends across STPs and indicates that each should be treated separately in studies designed to contribute to assessment of ecological risk. In this study, the St. Marys STP results point towards population level effects in a relatively large, tolerant, and mobile organism. The effects on other, more sensitive species and, perhaps, functional groups and the overall ecological outcome of this is unknown but must be 
considered when assessing any single species. Future studies should also incorporate analysis of STP effluent including chemical analysis, in vivo tests and wellcharacterised in vitro methods such as vitellogenin induction and receptor-binding assays.

\section{Conclusions}

The effluent of two STPs had different effects on the development of the modified hemal spines of G. holbrooki. At St. Marys differences in hemal spine morphology between fish upstream and downstream of the STP were not attributable to the presence of the STP. At Quakers Hill, results suggest that the effluent is generally estrogenic to G. holbrooki. There was a decrease in the proportion of males which were morphologically mature downstream of the St. Marys STP indicating potential population level effects associated with the presence of the STPs. The results of the current study highlight the importance of treating STPs separately when considering the potential ecological effects of their effluent and the difficulties in generalising beyond results obtained for a single pollutant source even over small spatial and technological scales. It is suggested that in future studies effluent be fully characterised and a wide range of tests (including in vitro, in vivo, and population level tests) be employed to investigate the potential for higher organisation level effects as are suggested by the results presented here.

\section{Funding sources}

This research was funded by an Australian Research Council (ARC) Linkage grant (LP0347743).

\section{Animal experiment approval}

Research was conducted with the approval of the UTS/ RNSH Animal Care and Ethics Committee (UTS/RNSH Protocol no. 0002-011A).

\section{References}

Angus, R.A., Weaver, S.A., Grizzle, J.M., Watson, R.D., 2002. Reproductive characteristics of male mosquitofish (Gambusia affinis) inhabiting a small southeastern US river receiving treated domestic sewage effluent. Environ. Toxicol. Chem. 21 (7), 1404-1409.

Baronti, C., Curini, R., D'Ascenzo, G., Di Corcia, A., Gentili, A., Samperi, R., 2000. Monitoring natural and synthetic estrogens at activated sludge sewage treatment works and in a receiving river water. Environ. Sci. Technol. 34 (24), 5059-5066.

Batty, J., Lim, R.P., 1999. Morphological and reproductive characteristics of male mosquitofish (Gambusia affinis holbrooki) inhabiting sewagecontaminated waters in New South Wales, Australia. Arch. Environ. Contam. Toxicol. 36, 301-307.

Bond, C.E., 1979. Biology of Fishes. W.B. Saunders and Company, Philadelphia.

Brennan, E.L., Lim, R.P., Laginestra, E., 2003. The use of poeciliids to assess the endocrine disrupting capacity of waters with reference to the mosquitofish inhabiting water bodies in the Sydney Olympic Park, Homebush Bay. In: Proceedings of Chemicals of Concern Water
Speciality Conference 2003; Chemicals of Concern in Water, Sydney, Australian Water Association and International Water Association, 8pp.

Collier, A., 1936. The mechanism of internal fertilisation in Gambusia. Copeia 1936 (1), 45-53.

Doyle, C.J., Lim, R.P., 2002. The effect of 17b-estradiol on the gonopodial development and sexual activity of Gambusia holbrooki. Environ. Toxicol. Chem. 21 (12), 2714-2719.

Doyle, C.J., Lim, R.P., 2005. Sexual behaviour and impregnation success of adult male mosquitofish following exposure to $17 \mathrm{~b}$-estradiol. Ecotoxicol. Environ. Saf. 61 (3), 392-397.

Doyle, C.J., Barker, J., Lim, R.P., Gray, L., 2003. Reproductive morphology of male mosquitofish (Gambusia holbrooki) inhabiting sewage-contaminated waters in the South Creek catchment of the Hawkesbury-Nepean River. In: Proceedings of Chemicals of Concern in Water Speciality Conference 2003; Chemicals of Concern in Water, Sydney, Australian Water Association and International Water Association, 10pp.

Jobling, S., Beresford, N., Nolan, M., Rodgers-Gray, T., Brighty, G.C., Sumpter, J.P., Tyler, C.R., 2002. Altered sexual maturation and gamete production in wild roach (Rutilis rutilis) living in rivers that receive treated sewage effluents. Biol. Reprod. 66, 272-281.

Kuntz, A., 1914. Notes on the habits, morphology of the reproductive organs, and embryology of the viviparous fish Gambusia affinis. Bull. Bureau Fish. 33, 177-190.

Lovell, A., Bickford, G., Fisher, J., Bailey, H., Elphik, J., Krassoi, R., 2000. Linking science stakeholders and management: targeting organophosphorus pesticide toxicity at STPs discharging to the Hawkesbury-Nepean River. In: Proceedings of the Conference, South Creek: Back From the Brink? Institute of Engineers, University of Western Sydney, Sydney.

Lye, C.M., Frid, C.L.J., Gill, M.E., McCormick, D., 1997. Abnormalities in the reproductive health of flounder Platichthys flesus exposed to effluent from a sewage treatment works. Mar. Pollut. Bull. 34 (1), 34-41.

Pawlowski, S., Ternes, T.A., Bonerz, M., Rastall, A.C., Erdinger, L., Braunbeck, T., 2004. Estrogenicity of solid-phase extracted water samples from two municipal sewage treatment plant effluents and river Rhine water using the yeast estrogen screen. Toxicol. In Vitro 18, $129-138$.

Porter, C.M., Janz, D.M., 2003. Treated municipal sewage discharge affects multiple levels of biological organisation in fish. Ecotoxicol. Environ. Saf. 54 (2), 199-206.

Purdom, C.E., Hardiman, P.A., Bye, V.J., Eno, N.C., Tyler, C.R., Sumpter, J.P., 1994. Estrogenic effects of effluents from sewage treatment works. Chem. Ecol. 8, 275-285.

Pyke, G.H., 2006. A review of the biology of Gambusia affinis and Gambusia holbrooki. Rev. Fish Biol. Fish. 15, 339-365.

Rawson, C., Lim, R.P., Warne, M.S.J., Doyle, C.J., 2006. The effect of $17 \mathrm{~b}$-estradiol on the development of modified hemal spines in early life-stage Gambusia holbrooki. Arch. Environ. Contam. Toxicol. 51, 253-262.

Rodgers-Gray, T.P., Jobling, S., Morris, S., Kelly, C., Kirby, S., Janbakhsh, A., Waldock, M., Sumpter, J.P., Tyler, C.R., 2000. Long-term temporal changes in the estrogenic composition of treated sewage effluent and its biological effects on fish. Environ. Sci. Technol. $34,1521-1528$.

Rosa-Molinar, E., Hendricks, S.E., Rodriguez-Sierra, J.F., Fritzsch, B., 1994. Development of the anal fin appendicular support in the western mosquitofish, Gambusia affinis affinis (Baird and Girard, 1854): a reinvestigation and reinterpretation. Acta Anat. (Basel) 151, 20-35.

Rosen, D.E., Gordon, M., 1953. Functional anatomy and evolution of male genitalia in Poeciliid fishes. Zoologica 38, 1-52.

Sydney Water, 2002a. Quakers Hill Sewage Treatment Plant. Sydney Water.

Sydney Water, 2002b. St Marys Sewage Treatment Plant. Sydney Water. 
Ternes, T.A., Kreckel, P., Mueller, J., 1999a. Behaviour and occurrence of estrogens in municipal sewage treatment plants-H. Aerobic batch experiments with activated sludge. Sci. Total Environ. 225, 91-99.

Ternes, T.A., Stumpf, M., Mueller, J., Haberer, K., Wilken, R.-D., Servos, M., 1999b. Behavior and occurrence of estrogens in municipal sewage treatment plants-I. Investigations in Germany, Canada and Brazil. Sci. Total Environ. 225, 81-90.

Turner, C.L., 1942. Morphogenesis of the gonopodial suspensoria in Gambusia ajjinis and the induction of male suspensoria! characters in the female by androgenic hormones. J. Exp. Zoo!. 91, 167-193. 